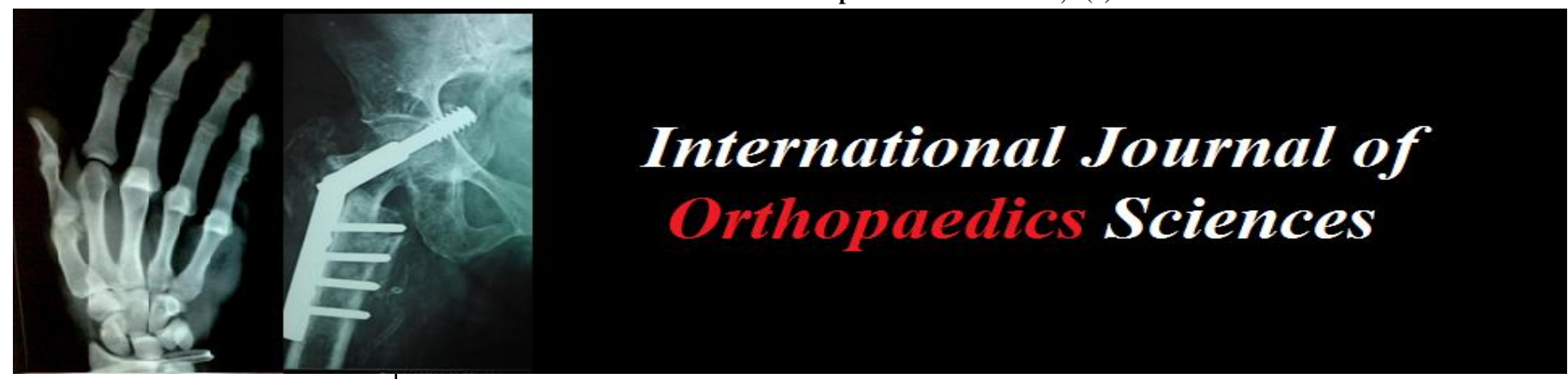

ISSN: $2395-1958$

IJOS 2018; 4(3): 290-293

(C) 2018 IJOS

www.orthopaper.com

Received: 22-05-2018

Accepted: 23-06-2018

Dr. Yeshwanth Subash D.N.B(Ortho), M.N.A.M.S, Department of Orthopaedics, Saveetha Medical College and Hospital, Thandalam, Chennai, Tamil Nadu, India

Dr. Kalanithi Ramanusan D.Ortho, Department of Orthopaedics, Saveetha Medical

College and Hospital,

Thandalam, Chennai,

Tamil Nadu, India

Dr. Jaganath Karunakaran M.B.B.S, Department of Orthopaedics, Saveetha Medical College and Hospital,

Thandalam, Chennai,

Tamil Nadu, India

Correspondence

Dr. Yeshwanth Subash

D.N.B(Ortho), M.N.A.M.S,

Department of Orthopaedics,

Saveetha Medical College and

Hospital, Thandalam, Chennai,

Tamil Nadu, India

\section{The role of core decompression in the management of early osteonecrosis of the femoral head}

\author{
Dr. Yeshwanth Subash, Dr. Kalanithi Ramanusan and Dr. Jaganath \\ Karunakaran
}

DOI: https://doi.org/10.22271/ortho.2018.v4.i3f.52

\section{Abstract}

Background: Osteonecrosis represents the death of cellular elements in the marrow which progresses in stages resulting in collapse of the femoral head and its treatment is stage specific. The aim of this study was to evaluate the role of Core decompression in the management of early osteonecrosis of the femoral head.

Methods: 15 patients with Stage 1 and 2 osteonecrosis of the femoral head were studied between January 2010 to January 2013 and were followed up for a period of 3 years.

Results: Mean age of the patients was 36.3 years ranging from 29 to 41 years. There was a male preponderance seen in our study. Chronic alcoholism was the most common etiological factor followed by idiopathic and steroid induced. The average pre-operative Harris hip score was 52 which significantly increased to 79.8 in the post-operative period. All patients reported excellent relief of pain in the immediate post-operative period due to resolution of bone marrow edema. Follow up MRI revealed resolution of necrosis in 10 hips with progression seen in 1 hip.

Conclusion: Core decompression is a safe, inexpensive procedure which gives good functional results in terms of pain relief and improvement in the quality of life for the patient if done in the early stages of Osteonecrosis before the onset of mechanical collapse of the femoral head.

Keywords: Osteonecrosis, femoral head, Ficat and Arlet, core decompression

\section{Introduction}

Osteonecrosis of the femoral head is characterized by death of the cellular elements of the marrow secondary to compromised blood supply which progresses in stages eventually leading to structural collapse of the femoral head ${ }^{[1-3]}$. Its most commonly seen in a younger age group usually in the third or fourth decade of life. Osteonecrosis occurs in fatty marrow which has a sparse blood supply. The femoral head is more prone to developing osteonecrosis due to the lack of a collateral circulation and due to the fact that it has relatively avascular sinusoids and bone marrow. The etiological factors are long term alcohol or steroid intake, collagen vascular disease, sickle cell disorders and coagulopathies ${ }^{[4-7]}$. Certain cases occur without any associated etiologic factor and are deemed to be idiopathic. Osteonecrosis has been classified into various stages and the most commonly followed classification is that by Ficat and Arlet. The management of osteonecrosis of the femoral head is based on the stage of the disease, onset of mechanical collapse and the sphericity of the femoral head. In the early stages before the onset of collapse, the aim of management would be to salvage the femoral head and to halt the progression of the disease. In later stages when the sphericity of the femoral head is no longer maintained due to structural collapse, replacement arthroplasty would be the preferred mode of management ${ }^{[8,9]}$. Core decompression is done upto stage $2 \mathrm{~A}$ of the disease in order to salvage the head and to prevent progression of the disease. The aim of this study was to evaluate the role of Core decompression in the management of early osteonecrosis of the femoral head and to compare the results with that of other authors as available in literature.

\section{Methods}

This was a prospective study of 15 patients with early osteonecrosis of the femoral head treated with Core decompression between January 2010 and January 2013. 
Skeletally mature patients with Ficat and Arlet stage 1 to $2 \mathrm{~A}$ osteonecrosis of the femoral head willing for the procedure and follow up were included in our study while skeletally immature patients, Ficat and Arlet stage 3 and 4 and patients not willing for follow up were excluded. For patients who presented to the outpatient department with history of groin pain radiating to the thigh with or without a limp, a thorough history was taken regarding alcohol consumption, steroid use, bleeding disorders and other causative factors. A thorough physical examination was done and the findings were recorded. The patients were then evaluated radiologically with standard X-rays of the pelvis with both hips-anteroposterior and lateral views. If the X-rays were normal and there was a high degree of suspicion for the presence of avascular necrosis, MRI of the affected hip was done with screening of the opposite hip due to the high degree of bilaterality seen in osteonecrosis. The MRI findings and the stage of the disease were noted and documented in the case records and the preoperative Harris hip score was also documented. The investigation was approved by the ethical commitee of our institution and a proper informed consent was taken from all the patients included in our study. The procedure was done under spinal anaesthesia with the patient on the fracture table in the supine position under intravenous antibiotic cover. Standard lateral approach was used to expose the proximal femur and a guide wire was passed with the entry point being distal to the greater trochanter and in a superolateral direction under fluoroscopic guidance. Reaming was then performed using an $8 \mathrm{~mm}$ reamer and after giving a thorough wound wash, closure was done in layers and sterile dressing was applied.
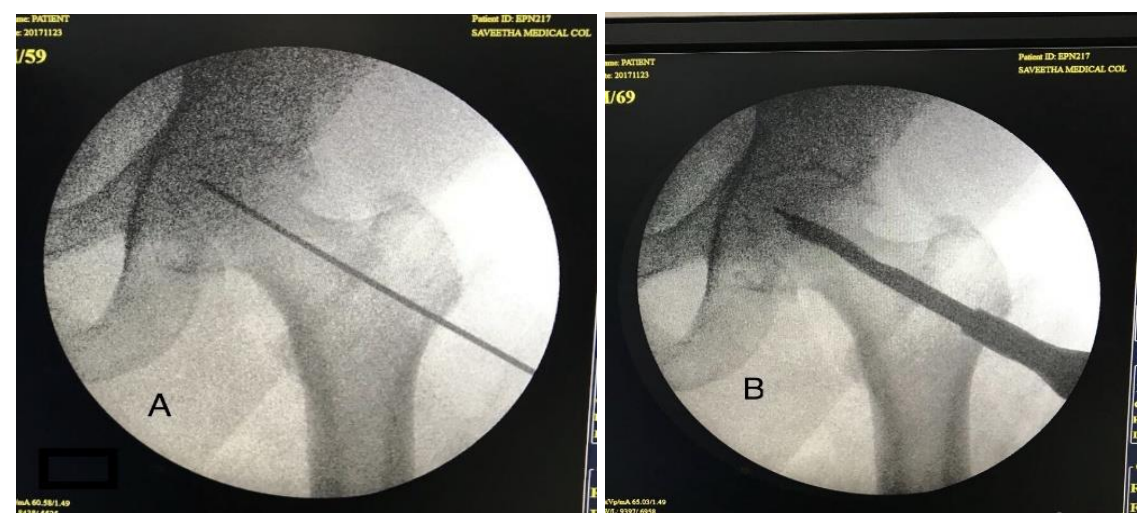

Fig 1: Illustrative case

A.Showing superolateral placement of the guide wire.

B. Reaming done with $8 \mathrm{~mm}$ reamer.

Bone grafting was not done in our series of cases. Intravenous antibiotics were given for 3 days. Active knee and ankle range of movements and quadriceps exercises were started on the same evening of surgery and the patients were mobilized on the first post-operative day with strict nonweight bearing walking with walking frame support and were advised to avoid bearing weight on the operated hip for a period of 6 weeks. Suture removal was done on the $12^{\text {th }}$ post-operative day. The patients were asked to follow up at 1, 3, 6 weeks and then at yearly intervals for three years. The clinical findings and the Harris hip score were documented in the case records. Follow up MRI was done in the immediate post-op period, at 6 months and then at the second and third year follow up and were evaluated for progression or resolution of the disease. The data collected was analyzed using IBM SPSS Version 22.0. Armonk, NY: IBM Corp. Chi square test was used in the comparison of categorical variables. A P value of less than 0.05 was considered to be statistically significant.

\section{Results}

The average age of the patients was 36.3 years ranging from 29-41 years.

Table 1: Age distribution

\begin{tabular}{|c|c|c|}
\hline Age(Years) & Number of patients & Percentage \\
\hline $21-30$ & 1 & 6.66 \\
\hline $31-40$ & 12 & 80 \\
\hline $41-50$ & 2 & 13.34 \\
\hline
\end{tabular}

There was a male preponderance seen in our study with 13 males and 2 females. The left side was more commonly affected and it was bilateral in 2 patients.

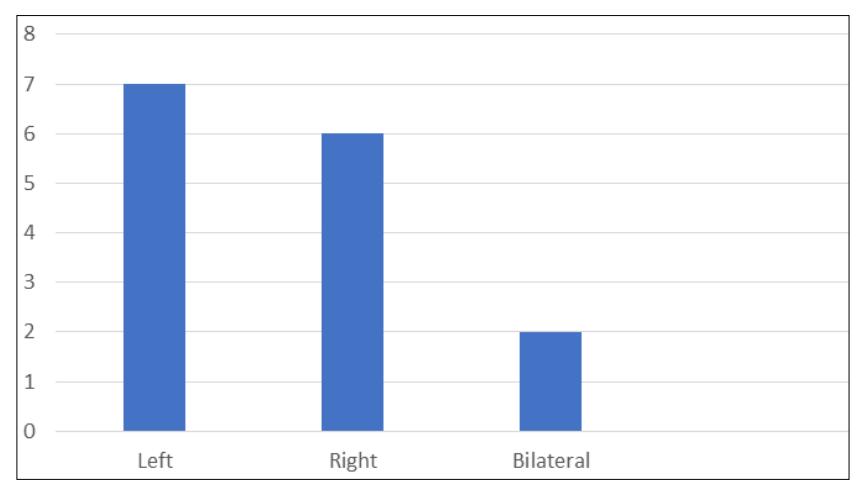

Fig 2: Side incidence

The most common etiological factor was chronic alcohol intake followed by idiopathic.

Table 2: Etiology

\begin{tabular}{|c|c|c|}
\hline Etiology & Number of patients & Percentage \\
\hline Idiopathic & 5 & 33.33 \\
\hline Long term Steroid usage & 8 & 53.33 \\
\hline Chronic alcoholism & 12 & 13.33 \\
\hline
\end{tabular}

There were 8 patients with Ficat and Arlet stage 1 and 7 patients with stage $2 \mathrm{~A}$. The average pre-operative Harris hip score was 52 ranging from 47 to 57 while it was an average of 79.8 ranging from 70 to 84 in the post-operative period. Preoperative MRI in all patients showed bone marrow edema with superolateral necrosis while post-operative scans showed 
resolution of bone marrow edema in all patients with 10 hips showing resolution of necrosis, unchanged in 6 hips and progression of necrosis was seen in 1hip. All patients experienced dramatic pain relief in the post-operative period following the procedure. There was progression of necrosis seen in one patient for whom it had led to collapse and loss of sphericity of the femoral head which necessitated a replacement arthroplasty at a later stage. All other patients had a spherical head till the time of the third year follow up. There were no iatrogenic complications encountered in our study.

\section{Discussion}

Osteonecrosis of the femoral is either idiopathic or associated with various etiological factors and progresses in stages. Initially a wedge shaped area of necrosis develops at the superior weight bearing area of the head and its followed by a reparative process. New woven bone is formed which ensheathes the necrotic trabeculae and due to the effect of shearing forces acting on that area a fracture occurs in between the repaired and unrepaired bone which is termed as the crescent sign and this represents the stage of mechanical collapse of the femoral head. Core decompression is the procedure of choice in the management of osteonecrosis of the femoral head upto stage $2 \mathrm{~A}$ before the onset of mechanical collapse. It does not have a role at a later stage when the sphericity of the femoral head is not maintained and other procedures such as rotational osteotomy or replacement arthroplasty needs to be done according to the stage of the disease and the extent of involvement of the head [10, 11] Patients with osteonecrosis present with history of hip pain with radiation to the thigh with or without a limp. The femoral head is richly supplied by venous sinusoids which have a large number of sensory fibres and the increase in the intraosseus pressure within the femoral head causes the hip pain. MRI of the patients taken pre-operatively demonstrated bone marrow edema in all the cases. The principles of core decompression are that it decreases the elevated intraosseus pressure and relieves venous stasis thereby relieving pain, provides a new channel for neovascularization and arrests or slows down progression of the disease. The advantages of core decompression are that it's a simple procedure, easy to perform, does not require prolonged stay in the hospital and the surgical field for subsequent arthroplasty if necessary, is not altered ${ }^{[12-14]}$. In a study by Steinberg MI, 308 patients with osteonecrosis of the femoral head were treated by core decompression and were followed up between 2 to 12 years. There was no progression of disease in $46 \%$ of the patients while $35 \%$ of the patients required a total hip arthroplasty but they were in stage 3 and $4{ }^{[15]}$. In a study by Carlos J et al., 42 patients were treated and followed up for a period of 2 years. The average pre-operative Harris hip score was 49 while it was 58 in the post-operative period. None of the cases in stage 1 showed progression of the disease while there were $17 \%$ in stage 2 and $66 \%$ in stage 3 with progression ${ }^{[16]}$. In a study by Smit N Shah et al., 20(28 hips) patients with osteonecrosis upto stage $2 \mathrm{~B}$ were treated and they showed excellent results in 19 cases, fair result in 1 hip and poor outcome in 8 hips. $92 \%$ of patients in stage 1 showed significant improvement while only 2 out of 4 hips in stage $2 \mathrm{~B}$ showed improvement [17]. A review of literature of studies of other authors also reported similar results ${ }^{[18-20]}$. In our study, we had 15 patients (17 hips) with 8 patients with stage 1 and 7 patients with stage 2A. All our patients presented with hip/groin pain with radiation the thigh with or without a limp. Core decompression was done and patients were followed up for a maximum period of 3 years. All patients experienced dramatic pain relief in the post-operative period which is attributed to the decrease in elevated intraosseus pressure and the resolution of venous stasis. MRI showed resolution of bone marrow edema in all the patients. The average preoperative Harris hip score was 52 ranging from 47 to 57 while it was an average of 79.8 ranging from 70 to 84 in the postoperative period. After 6 weeks of strict non weight bearing, patients were mobilized with full weight bearing and could return to their normal activities at an optimum functional level. Follow up scans had 10 hips showing resolution of necrosis, unchanged in 6 hips and progression of necrosis was seen in 1hip. There was progression of necrosis seen in one patient for whom the initial pain relief was good but not sustained and it had led to collapse and loss of sphericity of the femoral head which necessitated a replacement arthroplasty at a later stage. All other patients had a spherical head till the time of the third year follow up. None of our patients were lost to follow up. The limitations of our study were a small study group with a relatively short follow up period. From this study, we conclude that core decompression is a simple, easy to perform and an effective procedure which gives good results in terms of functional outcome and improves the quality of life for the patient provided that's its only performed upto stage $2 \mathrm{~A}$ before the onset of mechanical collapse of the femoral head.

\section{Conclusion}

From this study, we conclude that core decompression is a simple, easy to perform and an effective procedure which gives good results in terms of functional outcome and improves the quality of life for the patient provided that's its only performed upto stage $2 \mathrm{~A}$ before the onset of mechanical collapse of the femoral head.

\section{References}

1. Glimcher MJ, Kenzora JE. The biology of osteonecrosis of the human femoral head and its clinical implications: Part III, Discussion of the etiology and genesis of the pathological sequelae; comments on treatment. Clin Orthop Relat Res. 1979; 140:273-312.

2. Mankin HJ. Nontraumatic necrosis of bone (osteonecrosis). N Engl J Med. 1992; 326:1473-9.

3. Herndon JH, Aufranc OE. Avascular necrosis of the femoral head in the adult. A review of its incidence in a variety of conditions. Clin Orthop. 1972; 86:43-62.

4. Mont MA, Hungerford DS. Non-traumatic avascular necrosis of the femoral head. J Bone Joint Surg. 1995; 77A:459-474.

5. Ficat RP. Idiopathic bone necrosis of the femoral head: Early diagnosis and treatment. J Bone Joint Surg. 1985; 67B:3-9.

6. Weinstein SL, Buckwalter JA, editors. The adult hip. In: Turek s Orthopaedics: Principles and their Application. 6 th ed. Philadelphia: Lippincott Williams \& Wilkins, 2008, 533.

7. Shah KN, Racine J, Jones LC, Aaron RK. Pathophysiology and risk factors for osteonecrosis. Curr Rev Musculoskelet Med. 2015; 8:201-209.

8. Mont MA, Cherian JJ, Sierra RJ, Jones LC, Lieberman JR. Nontraumatic osteonecrosis of the femoral head: Where do we stand today? A ten-year update. J Bone Joint Surg Am. 2015; 97:1604-1627.

9. Steinberg ME, Brighton CT, Corces A, Hayken GD, 
Steinberg DR, Strafford B et al. Osteonecrosis of the femoral head. Results of core decompression and grafting with and without electrical stimulation. Clin Orthop RelatRes. [Clinical Trial Controlled Clinical Trial ResearchSupport, Non-U.S. Gov't]. 1989; (249):199-208.

10. Smith SW, Fehring TK, Griffin WL, Beaver WB. Core decompression of the osteonecrotic femoral head. J BoneJoint Surg Am. [Review]. 1995; 77(5):674-80.

11. Brown TD, Pedersen DR, Baker KJ, Brand RA. Mechanical consequences of core drilling and bonegrafting on osteonecrosis of the femoral head. J Bone Joint Surg Am. 1993; 75:1358-1367.

12. Camp JF, Calwelf CW. Core decompression of the femoral head for osteonecrosis. J Bone Joint Surg Am. 1986; 68:1313-1319.

13. Song WS et al. Results of multiple drilling compared with those of conventional methods of core decompression, Clin Orthop Relat Res. 2007; 454:139-46.

14. Maniwa S, Nishikori T, Furukawa S, Kajitani K, Iwata A, Nishikawa U et al. Evaluation of core decompression for early osteonecrosis of the femoral head. Arch Orthop Trauma Surg. 2000; 120(5-6):241. doi: 10.1007/s004020050456.

15. Steinberg ME. Core decompression of the femoral head for avascular necrosis: indications and results. Can J Surg. 1995; 38(1):S18-24.

16. Carlos Lavernia J, Rafael Sierra J. The Journal of Arthroplasty. 2000; 15(2):171-178.

17. Smit Shah N, Chirag Kapoor S, Maulik Jhaveri R, Paresh Golwala P, Sagar Patel. Analysis of outcome of avascular necrosis of femoral head treated by core decompression and bone grafting. J Clin Orthop Trauma. 2015; 6(3):160166.

18. Hopson CN, Siverhus SW. Ischemic necrosis of the femoral head. Treatment by core decompression. J Bone Joint Surg Am. 1988; 70(7):1048.

19. Robinson HJ Jr. Success of core decompression in the management of early stages of avascular necrosis: A four year prospective study. Proceedings of the American Academy of Orthopaedic Surgeons 59th Annual Meeting. Washington DC: Park Ridge, IL, American Academy of Orthopaedic Surgeons, 1992, 177.

20. Learmonth ID, Maloon S, Dall G. Core Decompression for Early Atraumatic Osteonecrosis of Femoral Head. J Bone Joint Surg. 1990; 72B:78-90. 